\title{
Baseline type 2 diabetes had a significant association with elevated high sensitivity cardiac troponin T levels in Chinese community-dwelling population: a 5-year prospective analysis
}

Shihui $\mathrm{Fu}^{1,2+}$, Rongjie $\mathrm{Jin}^{2+}$, Leiming Luo ${ }^{1 *}$ and Ping $\mathrm{Ye}^{1^{*}}$

\begin{abstract}
Background: The present analysis was designed to investigate the association of type 2 diabetes (T2D) with high sensitivity cardiac troponin T (hs-cTnT) during the 5 years of follow-up, and explore which one of fasting blood glucose (FBG) and postprandial blood glucose (PBG) is a determinant of this association in Chinese community-dwelling population.

Methods: This prospective community-based analysis was conducted based on 730 participants without coronary artery disease and hs-cTnT values $\geq 14 \mathrm{pg} / \mathrm{mL}$ receiving two measurements of hs-cTnT levels at baseline and follow-up of 5 years. Results: Prevalence of T2D was 16.2\% (118 participants). Median hs-cTnT levels were 4 (3-7) pg/mL and 6 (5-9) pg/mL at baseline and follow-up, respectively. The variation in hs-cTnT levels had a median of $2(0-4) \mathrm{pg} / \mathrm{ml}(p<0$. 001 for variation), and incidence of hs-cTnT levels $\geq 14 \mathrm{pg} / \mathrm{ml}$ was $7.1 \%$ (52 participants) at follow-up. T2D had a significant association with elevated hs-cTnT levels in multivariate Logistic regression models $(p<0.05)$. Elevated levels of PBG

$(p<0.05)$ rather than FBG $(p>0.05)$ determined the significant association with elevated hs-cTnT levels in multivariate linear regression models.

Conclusions: This community-based analysis observed that there was a significant increment of hs-cTnT levels, and baseline T2D had a significant association with elevated hs-cTnT levels during the 5 years of follow-up. Moreover, the present analysis demonstrated that PBG rather than FBG played a crucial role in this association in Chinese community-dwelling population without CAD.
\end{abstract}

Keywords: Chinese community-dwelling population, Fasting blood glucose, High sensitivity cardiac troponin T, Postprandial blood glucose, Type 2 diabetes

\footnotetext{
* Correspondence: Ileim@sina.com; sci301@126.com

${ }^{\dagger}$ Equal contributors

'Department of Geriatric Cardiology, Chinese People's Liberation Army

General Hospital, Beijing 100853, China

Full list of author information is available at the end of the article
} 


\section{Background}

Coronary artery disease (CAD) is a significant cause of death in community-dwelling population, and cardiac troponin $\mathrm{T}$ is a well-established biomarker providing the diagnostic and prognostic information in patients with CAD. CAD is very common in patients with type 2 diabetes (T2D), and cardiac troponin $\mathrm{T}$ is a big signal but not specific for CAD in patients with T2D. T2D has a significant association with cardiac troponin $\mathrm{T}$ measured with the conventional assay in patients with CAD [1]. However, the conventional assay is of limited use in patients without CAD, because they generally do not have detectable levels of cardiac troponin $\mathrm{T}$ using the conventional assay [2]. Recently, novel high sensitivity assay for cardiac troponin $\mathrm{T}$ with nearly ten times the detection limit of conventional assay has become available to further improve the diagnostic and prognostic performance of cardiac troponin $\mathrm{T}$ measured with the conventional assay [3-5]. Limited studies have probed the variation in high sensitivity cardiac troponin $\mathrm{T}$ (hs-cTnT) levels as well as the association of T2D with elevated hs-cTnT levels in community-dwelling population inclusive of patients with CAD. Previous cross-sectional and shortterm studies have demonstrated the relationships of hs-cTnT with cardiac structure and cardiovascular mortality, but been unable to identify the slight variation in hs-cTnT levels and analyze the association of T2D with elevated hs-cTnT levels [6, 7]. Long-term follow-up is needed to clarify whether T2D had a significant association with elevated hs-cTnT levels. Moreover, large-scale data from community-dwelling population rather than clinical patients are scarce, and most of published studies in community-dwelling population have included few Chinese [6, 7]. Small-scale studies on clinical patients restrict the interpretation of relationship between T2D and hs-cTnT in community-dwelling population, and results from western studies can not be directly taken to suggest the association T2D with elevated hs-cTnT levels in China [1, 2]. In this prospective analysis of Chinese community-dwelling population without CAD,

Table 1 Characteristics of participants divided by hs-cTnT levels $<14$ or $\geq 14 \mathrm{pg} / \mathrm{ml}$ at follow-up

\begin{tabular}{|c|c|c|c|c|}
\hline Characteristics & $\begin{array}{l}\text { Follow-up hs-cTnT } \\
<14 \mathrm{pg} / \mathrm{ml}(n=678)\end{array}$ & $\begin{array}{l}\text { Follow-up hs-cTnT } \\
\geq 14 \mathrm{pg} / \mathrm{ml}(n=52)\end{array}$ & $P$ value & $P$ value ${ }^{\dagger}$ \\
\hline \multicolumn{5}{|l|}{ At baseline } \\
\hline Age (year) & $58(50-67)$ & $72(64-75)$ & $<0.001$ & $<0.001$ \\
\hline Age $\geq 60(\%)$ & $317(46.8)$ & $45(86.5)$ & $<0.001$ & $<0.001$ \\
\hline Males (\%) & $274(40.4)$ & $35(67.3)$ & $<0.001$ & 0.009 \\
\hline $\mathrm{BMI}\left(\mathrm{kg} / \mathrm{m}^{2}\right)$ & $25.27(23.19-27.59)$ & $25.37(23.39-27.77)$ & 0.703 & 0.074 \\
\hline Obesity (\%) & $145(21.4)$ & $11(21.2)$ & 0.969 & 0.295 \\
\hline $\mathrm{SBP}(\mathrm{mmHg})$ & $126(114-140)$ & $131(121-144)$ & 0.034 & $<0.001$ \\
\hline $\mathrm{DBP}(\mathrm{mmHg})$ & 77(70-83) & 77(70-86) & 0.923 & 0.323 \\
\hline Hypertension (\%) & $302(44.5)$ & $29(55.8)$ & 0.117 & $<0.001$ \\
\hline $\mathrm{TG}(\mathrm{mmol} / \mathrm{L})$ & $1.47(1.05-2.15)$ & $1.49(1.18-2.11)$ & 0.788 & 0.020 \\
\hline High TG (\%) & 153(22.6) & $8(15.4)$ & 0.229 & 0.587 \\
\hline $\mathrm{HDL}-\mathrm{c}(\mathrm{mmol} / \mathrm{L})$ & $1.36(1.15-1.59)$ & $1.27(1.00-1.47)$ & 0.005 & 0.131 \\
\hline Low HDL-c (\%) & $88(13.0)$ & $14(26.9)$ & 0.005 & 0.309 \\
\hline LDL-c (mmol/L) & $2.92(2.47-3.30)$ & $3.02(2.47-3.37)$ & 0.637 & 0.690 \\
\hline High LDL-c (\%) & $42(6.2)$ & $1(1.9)$ & 0.207 & 0.430 \\
\hline Uric acid ( $\mu \mathrm{mol} / \mathrm{L})$ & $276(232-332)$ & $305(248-338)$ & 0.063 & $<0.001$ \\
\hline Hyperuricemia (\%) & $46(6.8)$ & $4(7.7)$ & 0.803 & 0.010 \\
\hline $\mathrm{FBG}(\mathrm{mmol} / \mathrm{L})$ & $4.95(4.51-5.45)$ & $4.94(4.38-5.77)$ & 0.897 & 0.835 \\
\hline PBG (mmol/L) & $6.34(5.23-8.30)$ & 7.57(5.72-10.95) & 0.006 & $<0.001$ \\
\hline T2D (\%) & $99(14.6)$ & 19(36.5) & $<0.001$ & 0.002 \\
\hline hs-cTnT (pg/ml) & $4(3-6)$ & $9(6-12)$ & $<0.001$ & $<0.001$ \\
\hline \multicolumn{5}{|l|}{ At follow-up } \\
\hline hs-cTnT (pg/ml) & $6(5-8)$ & $16(14-20)$ & $<0.001$ & $<0.001$ \\
\hline
\end{tabular}

"Comparison between groups defined by hs-CTnT levels $<14 \mathrm{pg} / \mathrm{mL}$ or $\geq 14 \mathrm{pg} / \mathrm{mL}$ at follow-up; ${ }^{\dagger}$ Bivariate correlation of all variables with the variation in hs-cTnT levels

Abbreviations: $h s-c T n T$ high sensitivity cardiac troponin T, BMI body mass index, SBP systolic blood pressure, $D B P$ diastolic blood pressure, $T G$ triglyceride, $H D L-c$ high density lipoprotein cholesterol, $L D L-c$ low density lipoprotein cholesterol, FBG fasting blood glucose, PBG postprandial blood glucose, $T 2 D$ type 2 diabetes 
Table 2 Characteristics of participants with and without T2D at baseline

\begin{tabular}{|c|c|c|c|}
\hline Characteristics & $\begin{array}{l}\text { With T2D } \\
(n=118)\end{array}$ & $\begin{array}{l}\text { Without T2D } \\
(n=612)\end{array}$ & $P$ value \\
\hline \multicolumn{4}{|l|}{ At baseline } \\
\hline Age (year) & $64(56-72)$ & $58(50-67)$ & $<0.001$ \\
\hline Age $\geq 60(\%)$ & $78(66.1)$ & $284(46.4)$ & $<0.001$ \\
\hline Males (\%) & $56(47.5)$ & 253(41.3) & 0.218 \\
\hline $\mathrm{BMI}\left(\mathrm{kg} / \mathrm{m}^{2}\right)$ & $26.16(23.87-28.72)$ & $25.15(23.16-27.34)$ & 0.008 \\
\hline Obesity (\%) & 39(33.1) & $117(19.1)$ & 0.001 \\
\hline $\mathrm{SBP}(\mathrm{mmHg})$ & $131(118-143)$ & 126(113-140) & 0.010 \\
\hline $\mathrm{DBP}(\mathrm{mmHg})$ & $79(70-82)$ & $77(70-83)$ & 0.566 \\
\hline Hypertension (\%) & $63(53.4)$ & $268(43.8)$ & 0.055 \\
\hline TG $(\mathrm{mmol} / \mathrm{L})$ & $1.85(1.25-2.55)$ & $1.44(1.02-2.07)$ & $<0.001$ \\
\hline High TG (\%) & $40(33.9)$ & $121(19.8)$ & 0.001 \\
\hline $\mathrm{HDL}-\mathrm{c}(\mathrm{mmol} / \mathrm{L})$ & $1.19(1.05-1.39)$ & $1.37(1.18-1.62)$ & $<0.001$ \\
\hline Low HDL-c (\%) & $24(20.3)$ & $78(12.7)$ & 0.029 \\
\hline LDL-c (mmol/L) & $2.98(2.38-3.35)$ & $2.92(2.47-3.30)$ & 0.611 \\
\hline High LDL-c (\%) & $9(7.6)$ & $34(5.6)$ & 0.382 \\
\hline Uric acid $(\mu \mathrm{mol} / \mathrm{L})$ & $282(232-349)$ & 278(234-331) & 0.625 \\
\hline Hyperuricemia (\%) & $11(9.3)$ & $39(6.4)$ & 0.245 \\
\hline FBG (mmol/L) & $6.69(5.47-8.10)$ & $4.87(4.44-5.24)$ & $<0.001$ \\
\hline PBG (mmol/L) & $12.9(9.70-16.46)$ & $5.96(5.06-7.30)$ & $<0.001$ \\
\hline hs-cTnT (pg/ml) & $5(3-9)$ & $4(3-6)$ & 0.001 \\
\hline \multicolumn{4}{|l|}{ At follow-up } \\
\hline hs-cTnT (pg/ml) & $8(6-11)$ & $6(5-8)$ & $<0.001$ \\
\hline
\end{tabular}

Abbreviations: $T 2 D$ type 2 diabetes, $B M I$ body mass index, SBP systolic blood pressure, DBP diastolic blood pressure, TG triglyceride, HDL-c high density lipoprotein cholesterol, $L D L$-c low density lipoprotein cholesterol, $F B G$ fasting blood glucose, $P B G$ postprandial blood glucose, $h s-c T n T$ high sensitivity cardiac troponin $T$

the follow-up of 5 years allowed us to have two measurements of hs-cTnT levels, and finally obtain the variation in hs-cTnT levels. Additionally, the present analysis attempted to investigate the association of baseline T2D with elevated hs-cTnT levels during the 5 years of follow-up, and explore which one of fasting blood glucose (FBG) and postprandial blood glucose (PBG) is a determinant of this association in Chinese communitydwelling population.

Table 3 Logistic regression model to analyze the association of T2D with hs-cTnT

\begin{tabular}{llll}
\hline Characteristics & HR & $95 \% \mathrm{Cl}$ & $P$ value \\
\hline First model $^{\mathrm{a}}$ & 2.473 & $1.292-4.732$ & 0.006 \\
Second model $^{\mathrm{b}}$ & 2.492 & $1.270-4.892$ & 0.008 \\
\hline
\end{tabular}

${ }^{\mathrm{a}}$ First model: adjusted for age and gender; ${ }^{\mathrm{b}} \mathrm{Second}$ model: adjusted for age, gender, obesity, hypertension, high triglyceride, low high density lipoprotein cholesterol, high low density lipoprotein cholesterol and hyperuricemia Abbreviations: T2D type 2 diabetes, hs-cTnT high sensitivity cardiac troponin T, $H R$ hazard ratio, $\mathrm{Cl}$ confidence interval
Table 4 Linear regression model to analyze the association of FBG and PBG with hs-cTnT

\begin{tabular}{lllllllll}
\hline Characteristics & FBG & & & & PBG & & \\
\cline { 2 - 4 } & Effect & SE & $P$ value & & Effect & SE & $P$ value \\
\hline First model $^{a}$ & 0.037 & 0.022 & 0.262 & & 0.075 & 0.009 & 0.027 \\
Second model $^{b}$ & 0.034 & 0.022 & 0.329 & & 0.072 & 0.009 & 0.038
\end{tabular}

${ }^{\mathrm{a}}$ First model: adjusted for age and gender; ${ }^{\mathrm{b}} \mathrm{Second}$ model: adjusted for age, gender, body mass index, systolic blood pressure, diastolic blood pressure, triglyceride, high density lipoprotein cholesterol, low density lipoprotein cholesterol and uric acid

Abbreviations: FBG fasting blood glucose, $P B G$ postprandial blood glucose, hs-CTnT high sensitivity cardiac troponin T, SE standard error

\section{Methods}

\section{Study population}

This prospective analysis was conducted based on 1680 community-dwelling residents with the age of 18 years or more voluntarily participating in a large medical check-up program at the health service centers in Beijing, China, from May 2007 to July 2009. In the first stage of sampling, three districts (Fengtai, Shijingshan and Daxing) were selected from 18 districts in Beijing. In the second stage of sampling, four communities were selected from these districts. In the third stage of sampling, participants were selected from these communities. The follow-up visit was conducted from February 2013 to September 2013. There were 181 participants lost, and follow-up of 5 years was completed for 1499 participants. Exclusion criteria were CAD [189 participants, diagnosed by chief physicians with history, symptoms of typical angina, cardiac markers and tests, such as electrocardiogram (resting/exercise), echocardiogram, radionuclide imaging, computed tomography and coronary arteriography, according to American College of Cardiology/American Heart Association/European Society of Cardiology guidelines], hs-cTnT levels $\geq 14 \mathrm{pg} / \mathrm{mL}$ (137 participants), missing values for variables (430 participants) and death (52 participants) [8-11]. Since the 99th percentile of hs-cTnT levels in normal population is $14 \mathrm{pg} / \mathrm{mL}$, the cut-point $14 \mathrm{pg} / \mathrm{mL}$ is recommended as diagnostic criteria of elevated hs-cTnT levels by standard specification of manufacturers. Remaining 730 participants had two measurements of hs-cTnT levels at baseline and follow-up. Baseline characteristics of participants were comparable before and after exclusion (Additional file 1: Table S1).

\section{Physical examination}

Physical examination was conducted by trained physicians. Weight was measured with a digital scale, and height was measured with a wall-mounted measuring tape, with light clothes and no shoes. Body mass index (BMI) was calculated as weight $(\mathrm{kg})$ divided by squared height $\left(\mathrm{m}^{2}\right)$. Two measurements of blood pressure were taken with a standard mercury sphygmomanometer 
(Yuwell Medical Equipment \& Supply Co., Ltd., Jiangsu, China) from the right arm of participants in the seated position, and systolic and diastolic blood pressures (SBP and DBP) were recorded as an average level of two measurements at intervals of at least $1 \mathrm{~min}$.

\section{Laboratory test}

Participants were fasting at least $12 \mathrm{~h}$ at the time of blood sample collection, and test was conducted by qualified technicians unaware of patients' characteristics in our central laboratory. Samples were stored at $-80^{\circ} \mathrm{C}$ and quantified using an Elecsys Troponin $\mathrm{T}$ high sensitive assay (Roche Products Ltd., Basel, Switzerland) on a Modular Analytics E170 autoanalyzer (Roche Products Ltd., Basel, Switzerland) by an electrochemiluminescence immunoassay method. Based on the standard specification of manufacturers, the lower limit of the high-sensitivity assay is $3 \mathrm{pg} / \mathrm{mL}$, whereas that of the conventional assay is $100 \mathrm{pg} / \mathrm{mL}$ (colloidal gold labeled method) or $10 \mathrm{pg} / \mathrm{mL}$ (chemiluminescence method). Concentrations of FBG, triglyceride (TG), high-density lipoprotein cholesterol (HDL-c) and low-density lipoprotein cholesterol (LDL-c) and uric acid were determined using the Roche enzymatic assay (Roche Products Ltd., Basel, Switzerland) on a Roche autoanalyzer (Roche Products Ltd., Basel, Switzerland). For participants receiving the collection of fasting blood sample, standard oral glucose tolerance test was conducted subsequently at timed intervals of $2 \mathrm{~h}$ after drinking 75 g glucose load.

\section{Diagnostic criteria}

Diagnostic criteria of hypertension were an average $\mathrm{SBP} \geq 140 \mathrm{mmHg}$, an average $\mathrm{DBP} \geq 90 \mathrm{mmHg}$, and/or an use of anti-hypertensive medications. Diagnostic criteria of T2D were FBG $\geq 7.0 \mathrm{mmol} / \mathrm{L}, \mathrm{PBG} \geq 11.1 \mathrm{mmol} /$ $\mathrm{L}$ and/or use of insulin or oral hypoglycemic medications. High TG was diagnosed as TG $\geq 2.26 \mathrm{mmol} / \mathrm{L}$ (200 mg/dl), low HDL-c as HDL-c $<1.04 \mathrm{mmol} / \mathrm{L}$ (40 mg/dL), and high LDL-c as LDL-c $\geq 4.14 \mathrm{mmol} / \mathrm{L}$ (160 mg/dL), and/or use of hypolipidemic medications. Hyperuricaemia was diagnosed as the levels of uric acid more than $360 \mu \mathrm{mol} / \mathrm{L}$ in women and more than $420 \mu \mathrm{mol} / \mathrm{L}$ in men [12].

\section{Statistical analysis}

Continuous variables with normal distribution were reported as mean with standard deviation, and continuous variables with skewed distribution were reported as median with interquartile range. Categorical variables were reported as number with proportion. Comparison between groups was conducted by Student's t-test (continouous variables with normal distribution), MannWhitney $U$ test (continouous variables with skewed distribution) and Chi-square test (categorical variables).
Bivariate correlation was derived from Pearson and Spearman correlations. Wilcoxon signed-rank test was applied to compare the hs-cTnT levels at baseline and follow-up. Logistic regression analysis was applied in two models. In the first model to include age and gender as adjustment variables, and in the second model the presence of age, gender, obesity, hypertension, high TG, low HDL-c, high LDL-c and hyperuricemia. The variation in hs-cTnT levels was transformed to meet the multinormality assumption, and then linear regression analysis was applied in two models. In the first model to include age and gender as adjustment variables, and in the second model the presence of age, gender, body mass index, SBP, DBP, TG, HDL-c, LDL-c and uric acid. Two sided $p<0.05$ was considered to indicate the statistical significance. Statistical analysis was conducted with Statistical Package for the Social Science (SPSS) software (version 17.0; SPSS Inc., Chicago, IL, USA).

\section{Results}

For all participants, median age was 59 (range: 25-89) years, and proportion of males was 42.3\% (309 participants). Prevalence of T2D was $16.2 \%$ (118 participants). Median hs-cTnT levels were 4 (3-7) pg/mL and 6 (5-9) $\mathrm{pg} / \mathrm{mL}$ at baseline and follow-up, respectively $(p<0.001$ for variation). Incidence of hs-cTnT levels $\geq 14 \mathrm{pg} / \mathrm{ml}$ was $7.1 \%$ (52 participants) at follow-up. Not only age, SBP and PBG levels were significantly higher, and HDLc levels were significantly lower, but also proportions of age $\geq 60$, males, low HDL-c and T2D were significantly higher in participants with hs-cTnT levels $\geq 14 \mathrm{pg} / \mathrm{ml}$ than those with hs-cTnT $<14 \mathrm{pg} / \mathrm{ml}$ at follow-up $(p<$ 0.05 for all; Table 1). The variation in hs-cTnT levels with a median of $2(0-4) \mathrm{pg} / \mathrm{ml}$ was related to not only levels of age, SBP, TG, uric acid and PBG, but also proportions of age $\geq 60$, males, hypertension, hyperuricemia and T2D ( $\mathrm{p}<0.05$ for all; Table 1$)$.

Compared with those without T2D, participants with T2D had not only significantly higher percentages of age $\geq 60$, obesity, high TG and low HDL-c, but also higher age, BMI, SBP, TG, FBG and PBG levels, and lower HDL-c levels, at baseline, as well as higher hscTnT levels at baseline and follow-up (Table 2). T2D had a significant association with elevated hs-cTnT levels in the first and second models $(p<0.05$; Table 3$)$. Elevated levels of PBG $(\mathrm{p}<0.05)$ rather than FBG $(p>0.05)$ determined the significant association with elevated hs-cTnT levels in the first and second models (Table 4).

\section{Discussion}

In Chinese community-dwelling population, the present analysis observed that there was a significant increment of hs-cTnT levels, and baseline T2D had a significant 
association with elevated hs-cTnT levels during the 5 years of follow-up. Moreover, the present analysis demonstrated that PBG but not FBG played a crucial role in this association in Chinese community-dwelling population without CAD.

As is well known, cardiac troponin $\mathrm{T}$ has clearly diagnostic and prognostic value in patients with CAD $[13,14]$. Mechanisms of cardiac troponin T elevation include the mismatch between oxygen supply and demand, inflammation, strain and apoptosis [15, 16]. Elevated levels of cardiac troponin $\mathrm{T}$ reflect the pathophysiological process of cardiovascular damage, and represent the rising morbidity and mortality of CAD. Compared with the conventional assay, novel high-sensitivity assay of cardiac troponin $\mathrm{T}$ had superior ability to improve the diagnosis of CAD and predict the outcome of CAD $[17,18]$. Thus, hs-cTnT is a significant biomarker to facilitate the early identification of CAD and define the risk of CAD in community-dwelling population.

CAD is very common in patients with $\mathrm{T} 2 \mathrm{D}$, and cardiac troponin $\mathrm{T}$ is a big signal but not specific for $\mathrm{CAD}$ in patients with T2D. Although T2D is a main factor affecting the cardiac troponin $\mathrm{T}$ measured with the conventional assay in clinical patients, the association of T2D with cardiac troponin $\mathrm{T}$ elevation measured with recently emergent high-sensitivity assay has not been explicit in community-dwelling population $[1,2]$. Largescale data from community-dwelling population rather than clinical patients are scarce, and most of published studies in community-dwelling population have included few Chinese [6, 7]. Small-scale studies on clinical patients restrict the interpretation of relationship between T2D and hs-cTnT in community-dwelling population, and results from western studies can not be directly taken to suggest the association of T2D with elevated hs-cTnT levels in China $[1,2]$. Meanwhile, previous cross-sectional and short-term studies have demonstrated the relationships of hs-cTnT with cardiac structure and cardiovascular mortality, but been unable to identify the slight variation in hs-cTnT levels and analyze the association of T2D with elevated hs-cTnT levels $[6,7]$. Long-term follow-up is needed to clarify whether T2D had a significant association with elevated hs-cTnT levels. Two measurements of hs-cTnT levels at baseline and follow-up of 5 years offered the opportunity for detecting the slight variation in hs-cTnT levels and evaluating the association of T2D with elevated hs-cTnT levels. The present analysis manifested a significant increment in hs-cTnT levels, and extended a significant association of baseline T2D with elevated hs-cTnT levels to Chinese community-dwelling population, reminding us that Chinese community-dwelling population without CAD have chronically elevated cardiac troponin $\mathrm{T}$ levels with the high sensitivity assay. Even slight alteration in cardiac troponin $\mathrm{T}$ levels is indicative of cardiovascular damage [19]. Moreover, results from the present analysis illustrated that cardiac troponin $\mathrm{T}$ was chronically elevated in response to T2D, and T2D accumulated the risk of cardiovascular damage in Chinese communitydwelling population without CAD.

Previous studies have failed to decide which one of FBG and PBG is a determinant of the association of T2D with elevated hs-cTnT levels in Chinese community-dwelling population without CAD. The present analysis underlined that the association of T2D with elevated hs-cTnT levels was attributed to PBG rather than FBG during the 5 years of follow-up. In other words, there was a significant role of elevated PBG levels in cardiovascular damage, and it should give priority to glycemic control after meals in Chinese community-dwelling population. However, the present paper have several limitations including a lack of full adjustment and residual confounding. Although the present analysis was adjusted for age, gender, body mass index, SBP, DBP, TG, HDL-c, LDL-c and uric acid, one possibility can not be ruled out that there are additional factors influencing hs-cTnT levels and these.potential confounders were not adjusted in the present analysis.

\section{Conclusions}

This community-based analysis observed that there was a significant increment of hs-cTnT levels, and baseline T2D had a significant association with elevated hs-cTnT levels during the 5 years of follow-up. Moreover, the present analysis demonstrated that PBG rather than FBG played a crucial role in this association in Chinese community-dwelling population without CAD.

\section{Additional file}

Additional file 1: Table S1. Characteristics of participants before and after exclusion at baseline. (DOC $25 \mathrm{~kb}$ )

\begin{abstract}
Abbreviations
CAD: Coronary artery disease; DBP: Diastolic blood pressure; FBG: Fasting blood glucose; HDL-c: Highdensity lipoprotein cholesterol; hs-cTnT: High sensitivity cardiac troponin T; LDL-c: Low-density lipoprotein cholesterol; PBG: Ostprandial blood glucose; SBP: Systolic blood pressure; T2D: Type 2 diabetes; TG: Triglycerides
\end{abstract}

\section{Acknowledgments}

We are grateful to all study participants for their participation in the study.

Funding

This work was supported by grants from National Key Basic Research Project (2012CB517503 and 2013CB530804), Health Special Scientific Research Project of Chinese People's Liberation Army (12BJZ34 and 14BJZ12), and Sanya Medical and Health Science and Technology Innovation Project (2016YW21). 


\section{Authors' contributions}

$F S, J R, L L, Y P$ : conceived and designed the experiments, performed the experiments, analyzed the data, contributed reagents/materials/analysis tools, and wrote the paper. All authors read and approved the final manuscript.

\section{Ethics approval and consent to participate}

The study protocol was approved by Ethics Committee of Chinese People's Liberation Army General Hospital (Beijing, China). Each participant provided written informed consent to be included in the study.

\section{Consent for publication}

Not applicable.

\section{Competing interests}

The authors have declared that no competing interests exist.

\section{Publisher's Note}

Springer Nature remains neutral with regard to jurisdictional claims in published maps and institutional affiliations.

\section{Author details}

'Department of Geriatric Cardiology, Chinese People's Liberation Army General Hospital, Beijing 100853, China. ²Department of Cardiology and Hainan Branch, Chinese People's Liberation Army General Hospital, Beijing, China.

Received: 18 January 2017 Accepted: 13 November 2017

Published online: 25 November 2017

\section{References}

1. Selvin E, Marinopoulos S, Berkenblit G, Rami T, Brancati FL, Powe NR, Golden SH. Meta-analysis: glycosylated hemoglobin and cardiovascular disease in diabetes mellitus. Ann Intern Med. 2004;141:421-31.

2. Wallace TW, Abdullah SM, Drazner MH, Das SR, Khera A, McGuire DK, Wians F, Sabatine MS, Morrow DA, de Lemos JA. Prevalence and determinants of troponin T elevation in the general population. Circulation. 2006;113:1958-65.

3. Latini R, Masson S, Anand IS, Missov E, Carlson M, Vago T, Angelici L, Barlera S, Parrinello G, Maggioni AP, Tognoni G, Cohn JN, Investigators V-H. Prognostic value of very low plasma concentrations of troponin $T$ in patients with stable chronic heart failure. Circulation. 2007;116:1242-9.

4. Omland T, de Lemos JA, Sabatine MS, Christophi CA, Rice MM, Jablonski KA, Tjora S, Domanski MJ, Gersh BJ, Rouleau JL, Pfeffer MA, Braunwald E, Prevention of Events with Angiotensin Converting Enzyme Inhibition (PEACE) Trial Investigators. A sensitive cardiac Troponin T assay in stable coronary artery disease. N Engl J Med. 2009;361:2538-47.

5. Lindahl $B$, Venge $P$, James $S$. The new high-sensitivity cardiac troponin $T$ assay improves risk assessment in acute coronary syndromes. Am Heart J. 2010;160:224-9.

6. Defilippi CR, de Lemos JA, Christenson RH, Gottdiener JS, Kop WJ, Zhan M, Seliger SL. Association of Serial Measures of cardiac Troponin T using a sensitive assay with incident heart failure and cardiovascular mortality in older adults. JAMA. 2010;304:2494-502.

7. de Lemos JA, Drazner MH, Omland T, Ayers CR, Khera A, Rohatgi A, Hashim I, Berry JD, Das SR, Morrow DA, McGuire DK. Association of troponin T detected with a highly sensitive assay and cardiac structure and mortality risk in the general population. JAMA. 2010;304:2503-12.

8. Fox K, Garcia MA, Ardissino D, Buszman P, Camici PG, Crea F, Daly C, De Backer G, Hjemdahl P, Lopez-Sendon J, Marco J, Morais J, Pepper J, Sechtem U, Simoons M, Thygesen K, Priori SG, Blanc JJ, Budaj A, Camm J, Dean V, Deckers J, Dickstein K, Lekakis J, McGregor K, Metra M, Morais J, Osterspey A, Tamargo J, Zamorano JL, Task Force on the Management of Stable Angina Pectoris of the European Society of Cardiology; ESC Committee for PracticeGuidelines (CPG). Guidelines on the management of stable angina pectoris: executive summary: the task force on the management of stable angina pectoris of the European society of cardiology. Eur Heart J. 2006;27:1341-81.

9. Anderson $J L$, Adams CD, Antman EM, Bridges CR, Califf RM, Casey DE Jr, Chavey WE 2nd, Fesmire FM, Hochman JS, Levin TN, Lincoff AM, Peterson ED, Theroux P, Wenger NK, Wright RS, Smith SC Jr, Jacobs AK, Adams CD, Anderson $J$, Antman EM, Halperin JL, Hunt SA, Krumholz HM, Kushner FG, Lytle BW, Nishimura R, Ornato JP, Page RL, Riegel B, American College of Cardiology; American Heart Association Task Force on Practice Guidelines
(Writing Committee to Revise the 2002 Guidelines for the Management of Patients With Unstable Angina/Non-ST-Elevation Myocardial Infarction); American College of Emergency Physicians; Society for Cardiovascular Angiography and Interventions; Society of Thoracic Surgeons; American Association of Cardiovascular and Pulmonary Rehabilitation; Society for Academic Emergency Medicine. ACC/AHA 2007 guidelines for the management of patients with unstable angina/non-ST-elevation myocardial infarction: a report of the American College of Cardiology/American Heart Association task force on practice guidelines developed in collaboration with the American College of Emergency Physicians, the Society for Cardiovascular Angiography and Interventions, and the Society of Thoracic Surgeons endorsed by the American Association of Cardiovascular and Pulmonary Rehabilitation and the Society for Academic Emergency Medicine. J Am Coll Cardiol. 2007;50:e1-e157.

10. Thygesen K, Alpert JS, White HD, Joint ESC/ACCF/AHAWHF Task Force for the Redefinition of Myocardial Infarction, Jaffe AS, Apple FS, Galvani M, Katus HA, Newby LK, Ravkilde J, Chaitman B, Clemmensen PM, Dellborg M, Hod H, Porela P Underwood R, Bax JJ, Beller GA, Bonow R, Van der Wall EE, Bassand JP, Wijns W, Ferguson TB, Steg PG, Uretsky BF, Williams DO, Armstrong PW, Antman EM, Fox KA, Hamm CW, Ohman EM, Simoons ML, Poole-Wilson PA, Gurfinkel EP, LopezSendon JL, Pais P, Mendis S, Zhu JR, Wallentin LC, Fernández-Avilés F, Fox KM, Parkhomenko AN, Priori SG, Tendera M, Voipio-Pulkki LM, Vahanian A, Camm AJ, De Caterina R, Dean V, Dickstein K, Filippatos G, Funck-Brentano C, Hellemans I, Kristensen SD, McGregor K, Sechtem U, Silber S, Tendera M, Widimsky P, Zamorano JL, Morais J, Brener S, Harrington R, Morrow D, Lim M, Martinez-Rios MA, Steinhubl S, Levine GN, Gibler WB, Goff D, Tubaro M, Dudek D, Al-Attar N. Joint ESC/ACC/ AHAMHF task force for the redefinition of myocardial infarction universal definition of myocardial infarction. Circulation. 2007;116:2634-53.

11. Giannitsis E, Becker M, Kurz K, Hess G, Zdunek D, Katus HA. High-sensitivity cardiac troponin $\mathrm{T}$ for early prediction of evolving non-ST-segment elevation myocardial infarction in patients with suspected acute coronary syndrome and negative troponin results on admission. Clin Chem. 2010;56:642-50.

12. Feig DI, Kang DH, Johnson RJ. Uric acid and cardiovascular risk. N Engl J Med. 2008;359:1811-21.

13. Yamaoka-Tojo M, Tojo T, Takahira N, Matsunaga A, Aoyama N, Masuda T, Izumi T. Elevated circulating levels of an incretin hormone, glucagon-like peptide-1, are associated with metabolic components in high-risk patients with cardiovascular disease. Cardiovasc Diabetol. 2010;9:17.

14. Atar D. New definition of myocardial infarction. BMJ. 2008:337:a3078.

15. Bakshi TK, Choo MK, Edwards CC, Scott AG, Hart HH, Armstrong GP. Causes of elevated troponin I with a normal coronary angiogram. Intern Med J. 2002;32:520-5.

16. Jeremias A, Gibson CM. Narrative review: alternative causes for elevated cardiac troponin levels when acute coronary syndromes are excluded. Ann Intern Med. 2005;142:786-91.

17. Keller T, Zeller T, Peetz D, Tzikas S, Roth A, Czyz E, Bickel C, Baldus S, Warnholtz A, Fröhlich M, Sinning CR, Eleftheriadis MS, Wild PS, Schnabel RB, Lubos E, Jachmann N, Genth-Zotz S, Post F, Nicaud V, Tiret L, Lackner KJ Münzel TF, Blankenberg S. Sensitive troponin I assay in early diagnosis of acute myocardial infarction. N Engl J Med. 2009;361:868-77.

18. Reichlin T, Hochholzer W, Bassetti S, Steuer S, Stelzig C, Hartwiger S, Biedert S, Schaub N, Buerge C, Potocki M, Noveanu M, Breidthardt T, Twerenbold R, Winkler K, Bingisser R, Mueller C. Early diagnosis of myocardial infarction with sensitive cardiac troponin assays. N Engl J Med. 2009;361:858-67.

19. Miller WL, Hartman KA, Burritt MF, Grill DE, Jaffe AS. Profiles of serial changes in cardiac troponin T concentrations and outcome in ambulatory patients with chronic heart failure. J Am Coll Cardiol. 2009:54:1715-21. 